\title{
Do sputum eosinophils and ECP relate to the severity of asthma?
}

\author{
M.C. Ronchi**, C. Piragino*, E. Rosi*, L. Stendardi**, A. Tanini*, \\ G. Galli*, R. Duranti*, G. Scano*
}

Do sputum eosinophils and ECP relate to the severity of asthma? M.C. Ronchi, C. Piragino, E. Rosi, L. Stendardi, A. Tanini, G. Galli, R. Duranti, G. Scano. @ERS Journals Ltd 1997.

ABSTRACT: There is much evidence that eosinophils play an important role in bronchial epithelial damage in asthma by releasing cationic proteins. However, the extent to which eosinophil inflammation relates to indices of asthma severity in chronic stable asthma is still a matter of debate.

We studied 46 clinically stable patients with mild to severe chronic asthma (forced expiratory volume in one second (FEV1) 50-126\% of predicted value). The clinical severity of asthma was graded from 1 to 4 according to the Aas scoring system. Twelve normal subjects were also studied as controls. Induction of sputum was performed by hypertonic saline to determine differential cell count, and eosinophil cationic protein (ECP) by the so-called "plug technique". The concentration of ECP was measured by a fluoroimmunoassay. Bronchial hyperresponsiveness was recorded by inhaling progressive concentrations of histamine, and the concentration that caused a $20 \%$ decrease in FEV1 (PC20) was calculated.

Sputum eosinophils (range 0-61\%), sputum ECP (range 24-10,800 $\mathrm{\mu g} \cdot \mathrm{L}^{-1}$ ) and serum ECP (range 4-61 $\mu \mathrm{g} \cdot \mathrm{L}^{-1}$ ) were significantly greater in asthmatics than in normal subjects, and distinguished the most severe group with the highest Aas score from the others. Sputum eosinophils and sputum ECP were strongly related to each other. The relationships between sputum or serum ECP and PC20 (range 0.016-7.5 $\mathrm{mg} \cdot \mathrm{mL}^{-1}$ ), and between sputum ECP and FEV1 were found to be weak.

In conclusion, sputum outcomes of eosinophil activation and serum eosinophilic cationic protein appear to be useful indicators of disease. They do not accurately reflect current clinical or functional indices of asthma severity in chronic stable patients, and might therefore provide complementary data disease monitoring. Eur Respir J 1997; 10: 1809-1813.
*Section of Respiratory Medicine, Istituto di Medicina Interna ed Immunoallergologia, University of Florence, Florence, Italy. ***Fondazione Pro Juventute Don C. Gnocchi, Pozzolatico, Florence, Italy

Correspondence: G. Scano Istituto di Medicina Interna ed Immunoallergologia

Università degli Studi di Firenze

V. le Morgagni 85

50134 Firenze

Italy

Keywords: Asthma

eosinophilic cationic protein sputum

Received: September 201996 Accepted after revision April 31997
An extensive eosinophilic inflammation of the bronchi has recently been described in bronchial asthma, even with mild clinical or subclinical disease [1-3]. Activated eosinophils are able to release many cytotoxic proteins, including eosinophil cationic protein (ECP), which has a central role in bronchial epithelial damage $[4,5]$. The role of blood eosinophils and serum ECP in monitoring disease activity in chronic asthma has not been conclusively defined, as there is conflicting evidence concerning their relationship to clinical severity of disease [6-10].

The use of spontaneously produced or induced sputum, proposed as a reliable and noninvasive method to characterize airway inflammation [11-14], appears promising for clinical survey and longitudinal studies with asthmatic patients. In line with previous studies showing that the degree of eosinophil activation is more important than the increase in number of eosinophils in reflecting an ongoing inflammation in asthma [15], VIRCHOW et al. [16] have shown that the level of sputum ECP, rather than the number of sputum eosinophils, correlates with lung function in asthma. However, that study relied upon a small number of asthmatic patients, in whom the indices of asthma severity, such as clinical scores, duration of disease, and bronchial hyperresponsiveness, were not defined.

Therefore, we carried out the present study in a group of patients with clinically defined chronic stable asthma to verify whether and to what extent ECP and eosinophil differential counts in sputum and blood relate to the indices of asthma severity.

\section{Materials and methods}

\section{Subjects}

Forty six out-patients ( 30 males and 16 females) aged 17-73 (median 41) yrs with chronic bronchial asthma according to the criteria of the National Heart, Lung and Blood Institute (NHLBI) [17], and a group of normal subjects, participated in the study. Thirty patients were nonsmokers, 16 were exsmokers (with less than 10 packyrs). Informed consent was given by each subject and the study was approved by the local Ethics Committee.

Asthma was characterized by episodes of dyspnoea with wheezing, variable airflow limitation with reversible 
obstruction ( $\geq 20 \%$ increase in FEV1 after inhalation of $200 \mu \mathrm{g}$ of fenoterol), positive response to inhalation challenge with histamine (provocation concentration producing a $20 \%$ fall in forced expiratory volume in one second $\left.(\mathrm{PC} 20) \leq 8 \mathrm{mg} \cdot \mathrm{mL}^{-1}\right)$. The clinical severity of asthma was graded from 1 to 4 according to the scoring system of AAs [18]. Before entering the study, 15 patients required daily inhaled corticosteroids and bronchodilators. Bronchodilators, but not corticosteroids, had been withheld for at least $12 \mathrm{~h}$ before each study. All subjects had been free from acute respiratory infections within the preceding 4 weeks and were stable at the time of study.

The normal subjects were an age-matched group: 12 healthy, lifelong nonsmokers, with negative skin-prick tests, aged 25-65 (median 34) yrs, without symptoms of asthma, and with normal bronchial responsiveness to histamine (PC20 $\geq 16 \mathrm{mg} \cdot \mathrm{mL}^{-1}$ ). Their pulmonary function was in the normal range (forced expiratory volume in one second $(\mathrm{FEV} 1)>80 \%$ of predicted, FEV1/vital capacity $(\mathrm{VC})>70 \%$ ).

\section{Aas score}

According to the Aas score, the clinical severity of asthma ranges from very mild forms (score 1) to incapacitating forms (score 5). Grading is based on: the number and duration of asthma episodes; the total duration of symptoms; the presence or absence of symptom-free intervals between attacks; and the requirement for medication over 1 yr [18]. In this study, clinical severity of asthma was graded from 1 (very mild asthma) to 4 (severe asthma): in 14 patients asthma was scored 1 ; in 11 it was scored 2; in 17 it was scored 3; and in 4 it was scored 4.

\section{Diagnosis of immediate-type hypersensitivity}

Allergy tests, including a battery of common aeroallergen extracts, were performed by the skin-prick method. Cutaneous positivity to allergen was defined by a wheal (>3 mm) and erythema with pseudopods. Common aeroallergens included mixed graminaceous pollen, mixed composite pollen, Parietaria officinalis, olive pollen, Alternaria, Aspergillus fumigatus, Cladosporium, Dermatophagoides pteronyssinus, Dermatophagoides farinae and cat and dog danders.

\section{Lung function}

Baseline pulmonary function testing was performed by measuring static and dynamic lung volumes using a water-sealed spirometer (Pulmonet Godart; Sensormedics Corp., Yorba Linda, CA, USA), as reported previously [19]. The normal values for lung volumes were those proposed by the European Coal and Steel Community [20].

\section{Bronchial challenge}

Each patient was administered a histamine aerosol inhalation test. Increasing concentrations of histamineacid phosphate in normal phosphate buffered saline (pre- pared by the University Hospital Pharmacy) were inhaled from a DeVilbiss 646 nebulizer (DeVilbiss Co., Somerset, PA, USA), driven at an airflow rate of $6 \mathrm{~L} \cdot \mathrm{min}^{-1}$, mean (SD) output $0.31(0.03) \mathrm{mL} \cdot \mathrm{min}^{-1}$, using the tidal breathing method. With this method, $4 \mathrm{~mL}$ of solution were placed in the nebulizer and inhalation continued during tidal breathing over $2 \mathrm{~min}$. Histamine solution was stored at $4^{\circ} \mathrm{C}$ and nebulized at room temperature. Normal phosphate-buffered saline was inhaled first, followed at 5 min intervals by histamine in twofold increasing concentrations from 0.031 to $8 \mathrm{mg} \cdot \mathrm{mL}^{-1}$. The test was withheld at the concentration of histamine which caused a decrease in FEV $1 \geq 20 \%$ from saline (provocative concentration). The $\mathrm{PC} 20$ was determined from the log doseresponse curve. Details of the technique have been described previously [21].

\section{Induction and analysis of sputum}

Induction of sputum was performed according to the method of PIN et al. [12]. Ten minutes after fenoterol inhalation $(200 \mu \mathrm{g})$, hypertonic saline was nebulized with an ultrasonic nebulizer (Fisoneb; Fisons Corp., Rochester, NY, USA) and was inhaled for 5 min periods up to $20 \mathrm{~min}$. The concentration of saline was increased at $10 \mathrm{~min}$ intervals from 3 to $4 \%$. FEV1 was measured every five minutes during inhalation of hypertonic saline solution. The sputum induction procedure did not cause troublesome symptoms, and the FEV1 did not decrease by more than $20 \%$ in any subject. Every 5 min, subjects were asked to try to cough sputum into a Petri dish and to collect saliva in a separate container. Macroscopic characteristics of the sputum were recorded, and the quality of sputum sample was assessed, according to the method of PIN et al. [12], by the number of lower respiratory tract plugs and the extent of salivary contamination in cell counts.

Cytological analysis. Two to three plugs free of salivary contamination were suspended in dithiothreitol (DTT) solution $(0.1 \%)$ and incubated for $30 \mathrm{~min}$ at $37^{\circ} \mathrm{C}$ for slide making. Cells were centrifuged at $1,500 \mathrm{rpm}$ for $10 \mathrm{~min}$ and then resuspended in saline. Three sputum slides were then prepared for cytological examination by cytocentrifugation. Cells were air-dried and stained with May-Grünwald Giemsa stain. Cell differentials were determined by counting 200 nonsquamous cells on each sputum slide.

ECP measurement. The volume of the remaining portion of sputum samples was determined and an equal volume of dithiothreitol $(0.1 \%)$ was added. The samples were mixed by vortex and incubated at $37^{\circ} \mathrm{C}$ for $20 \mathrm{~min}$. The samples were then centrifuged at $1000 \times \mathrm{g}$ for $10 \mathrm{~min}$. The supernatants were aspirated and frozen at $-70^{\circ} \mathrm{C}$ for later ECP analysis.

ECP was assessed both in sputum and blood by a fluoroimmunoassay (CAP ECP FEIA; Kabi Pharmacia, Pharmacia Diagnostics AB, Uppsala, Sweden). Sputum specimens needed to be diluted 1:20 in 48\% of cases and 1:80 in $16 \%$. Anti-ECP, covalently coupled to immunoCAP, reacted with the ECP in the specimens. After washing, enzymelabelled antibodies against ECP were added to form a complex. After incubation, unbound enzyme anti-ECP 
was washed away and the bound complex was then incubated with a developing agent. After stopping the reaction, the fluorescence of the eluate was measured in Fluoro-Count 96 (Kabi Pharmacia). The sensitivity of this technique is $<0.5 \mu \mathrm{g} \cdot \mathrm{L}^{-1}$.

\section{Serum ECP}

Blood was collected using silicone-containing tubes $(4 \mathrm{~mL}$ Vacutainer hemogard SST tubes; Becton Dickinson Vacutainer Systems Europe, Meylan, France) for serum separation. After clotting for $60-120 \mathrm{~min}$ at room temperature $\left(22-24^{\circ} \mathrm{C}\right)$, serum samples were centrifuged at the same temperature at $1,000 \times \mathrm{g}$ for $15 \mathrm{~min}$ and aliquoted and frozen at $-20^{\circ} \mathrm{C}$ for subsequent assay of ECP using the same technique (CAP ECP FEIA; Kabi Pharmacia).

ECP was determined in duplicate both in serum and in sputum. The normal range for serum ECP was 2.8-9.0 $\mu \mathrm{g} \cdot \mathrm{L}^{-1}$ and for sputum ECP 7.1-70.0 $\mu \mathrm{g} \cdot \mathrm{L}^{-1}$.

\section{Study design}

The patients were examined on three occasions within a 6 day period. On day 1, a questionnaire on the subject's characteristics and clinical scores was completed. Baseline spirometry and skin-prick tests were also performed. On day 2, the histamine inhalation test was performed. On day 3 (at least $48 \mathrm{~h}$ after the histamine challenge), sputum induction and drawing for serum ECP were carried out. All of the sputum from normal subjects and asthmatic patients was collected as induced sputum.

Ten patients and five normal subjects were asked to produce sputum on a second occasion within 6 days.

In a complementary study carried out in eight subjects (three mild asthmatics, two moderate asthmatics, and three normals), the sputum induction and the drawing for serum ECP were performed 24 before, and 24 and $48 \mathrm{~h}$ after the histamine challenge.

\section{Statistical analysis}

The repeatability of duplicate measurements of cell profile and ECP was assessed by the coefficient of repeatability (CoR). ECP concentrations were log-transformed before analysis, because differences between the two measurements were proportional to their mean value, and CoR was expressed as antilog [22]. The effects of histamine challenge on sputum eosinophils and ECP levels were assessed by two-way analysis of variance (ANOVA). Regression analysis was performed by Spearman's rank correlation coefficient. The significance of the differences between groups was assessed by Kruskal-Wallis analysis of variance, and Mann-Whitney U-test when appropriate. Bonferroni's adjustment $(0.05 / \mathrm{n}$ test $)$ for multiple testing was used. A p-value less than 0.05 was considered to be significant.
Table 2. - Sputum cellular and biochemical profile

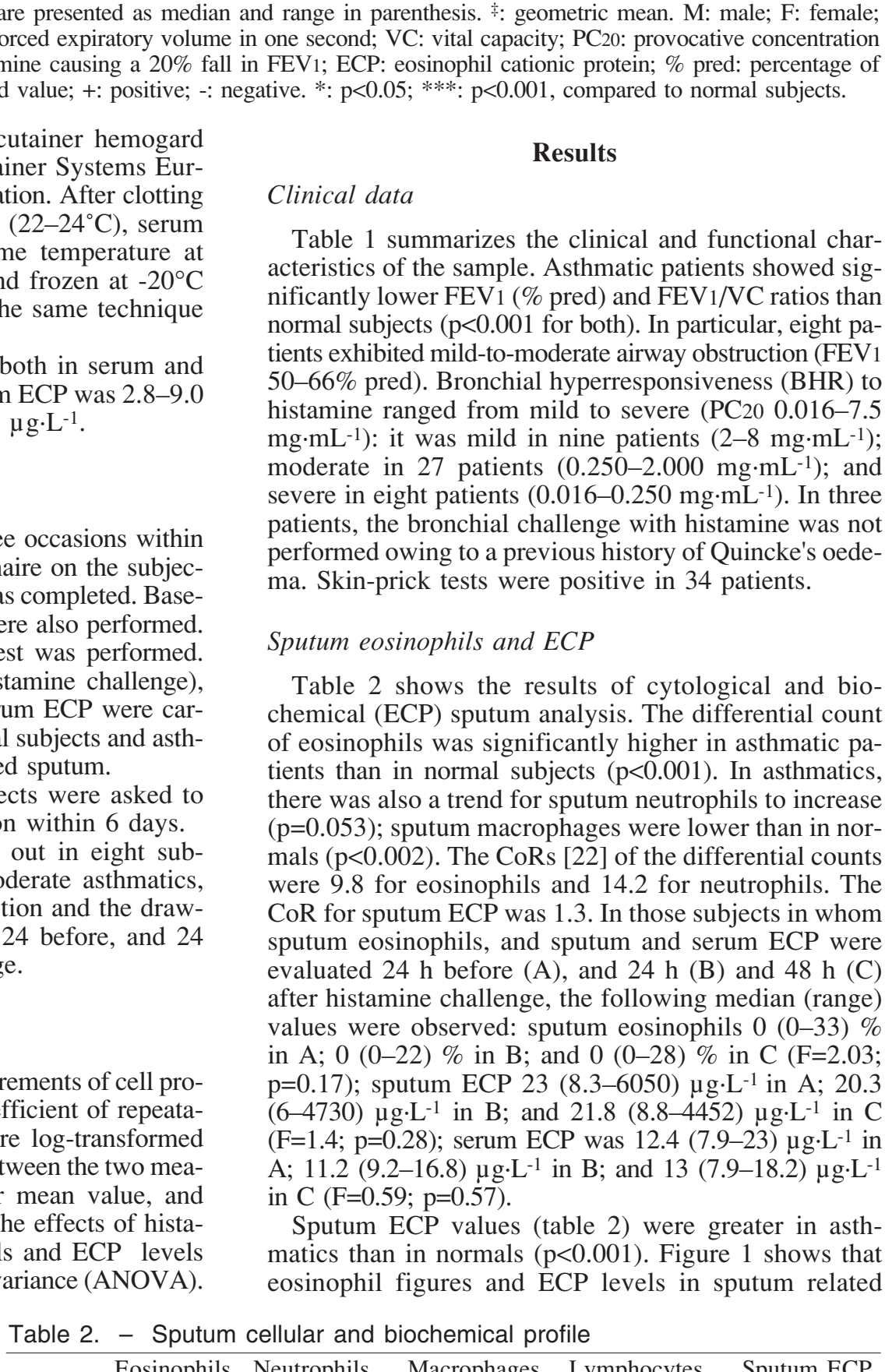

\begin{tabular}{lccccc}
\hline & $\begin{array}{c}\text { Eosinophils } \\
\%\end{array}$ & $\begin{array}{c}\text { Neutrophils } \\
\%\end{array}$ & $\begin{array}{c}\text { Macrophages } \\
\%\end{array}$ & $\begin{array}{c}\text { Lymphocytes } \\
\%\end{array}$ & $\begin{array}{c}\text { Sputum ECP } \\
\mu \mathrm{g} \cdot \mathrm{L}^{-1}\end{array}$ \\
\hline Asthma & $5.3 * * *$ & 17.7 & $66.2^{\# \#}$ & 1.4 & $528.5^{* * * *}$ \\
$(\mathrm{n}=46)$ & $(0-60.9)$ & $(1.7-61)$ & $(13.6-93)$ & $(0-8)$ & $(24-10800)$ \\
Normal & 0 & 9.4 & 87.5 & 1.16 & 16.5 \\
$(\mathrm{n}=12)$ & $(0-2.2)$ & $(0-25)$ & $(0-97)$ & $(0-2)$ & $(7.1-70)$ \\
\hline
\end{tabular}

Values are presented as median and range in parenthesis. ECP: eosinophil cationic protein. \#\#: $\mathrm{p}<0.002 ; * * *$ : $<<0.001$, compared to normal subjects. 


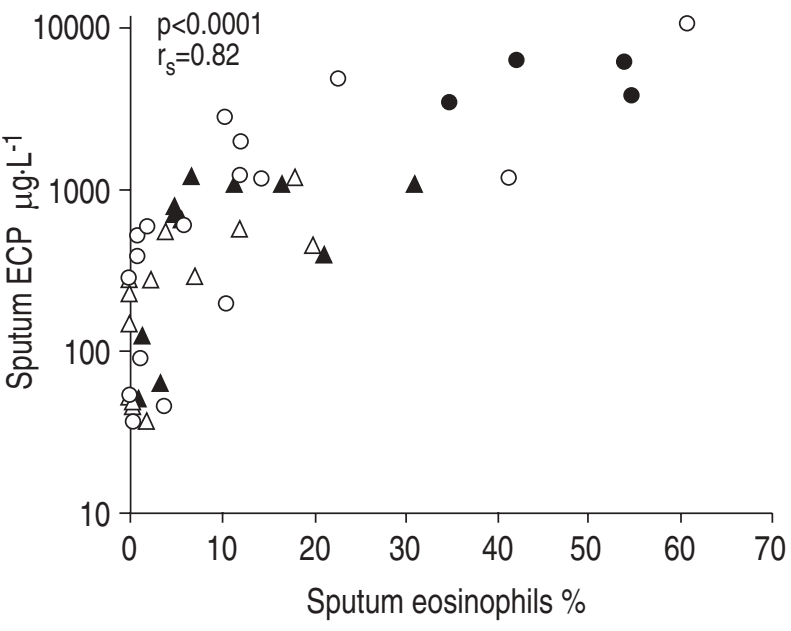

Fig. 1. - Relationship between sputum eosinophil cationic protein (ECP) and sputum eosinophils in asthmatic patients. $\Delta$ : Aas score 1;

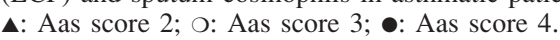

strongly to each other $\left(\mathrm{r}_{\mathrm{s}}=0.82 ; \mathrm{p}<0.0001\right)$; the figure also shows that $55.5 \%$ of patients with no sputum eosinophils had sputum ECP above the range calculated for the normal control group $\left(<70 \mu \mathrm{g} \cdot \mathrm{L}^{-1}\right)$. In figure 1 , asthmatics were divided according to their clinical severity (Aas score): sputum eosinophils and sputum ECP were greater in each scoring group than in normals $(\mathrm{p}<0.05$ to $\mathrm{p}<0.016$ ). However, eosinophils only permitted the differentiation of group 4 from groups 1-3, whilst ECP differentiated group 4 from groups 1 and 2 ( $p<0.05$ to $\mathrm{p}<0.015$ for all comparisons).

Eosinophils and ECP related to clinical scores (Aas) $\left(r_{s}=0.40 ; p<0.008\right.$ and $r_{s}=0.50 ; p<0.008$, respectively $)$. ECP weakly related to FEV1 \% pred $\left(r_{s}=-0.34 ; p<0.02\right)$ and $\mathrm{PC} 20\left(\mathrm{r}_{\mathrm{s}}=-0.40 ; \mathrm{p}=0.01\right)$, and eosinophils did not.

There were no differences in sputum eosinophils and ECP between treated and nontreated patients, or between allergic and nonallergic patients. In all subgroups sputum eosinophils and ECP related to each other $(\mathrm{p}<0.005$ to $\mathrm{p}<0.0001$ ). In addition, in all subgroups, but not in allergic patients, sputum eosinophils $(\mathrm{p}<0.05$ to $\mathrm{p}<0.0009)$ and ECP $(p<0.05$ to $p<0.003)$ related to clinical scores.

\section{Blood eosinophils and serum ECP}

Blood eosinophils were $>500$ cells $\cdot \mathrm{mm}^{-3}$ in eight of the 46 patients. Compared to normal subjects, serum ECP level was significantly higher in asthmatics as a group $(\mathrm{p}<0.001)$ (table 1), and in 1, 2 and 3 scoring groups. In contrast, no difference was found between scoring groups. Serum ECP was above the normal range in 32 patients (median 14.8 (range $3.5-60.6) \mu \mathrm{g} \cdot \mathrm{L}^{-1}$ ).

Blood eosinophils were not related to serum ECP or sputum eosinophils. Serum outcomes were not related to clinical scores or percentage predicted FEV1, while serum ECP was weakly related to $\mathrm{PC}_{20}\left(\mathrm{r}_{\mathrm{s}}=-0.34 ; \mathrm{p}=0.04\right)$.

\section{Discussion}

Sputum eosinophils, and sputum and serum ECP were useful for differentiating asthmatic patients from normal subjects; however, their usefulness for differentiating clinical subgroups was limited. Sputum outcomes significantly related to each other. Sputum ECP but not sputum eosinophils weakly related to baseline pulmonary function, as did the degree of bronchial hyperresponsiveness both to sputum and serum ECP.

Recent studies have proposed the analysis of induced sputum as a reliable and noninvasive method to investigate airway inflammation in asthmatic patients [11-14]. The results of the present investigation are in line with those of our previous study [21], and with the results of studies carried out either with biopsies [1-3] or bronchoalveolar lavage (BAL) [8], indicating the importance of eosinophilic airway inflammation in the pathogenesis of chronic stable asthma. The biochemical analysis of sputum also provides several indices of eosinophil activation, such as major basic protein (MBP) and ECP. ECP was measured in the entire sample of induced sputum and expressed as the level per millilitre of sputum supernatant. In an attempt to limit salivary contamination, we asked the patients to collect saliva in a separate container.

As in the study by FAHY et al. [13], in the present study the level of sputum ECP was lower in normal subjects than in asthmatics. The normal values of sputum ECP were similar in the two studies. On the contrary, sputum ECP from asthmatic patients showed a wider range and higher mean values than in the study by FAHY et al. [13]. This might be due to the different method of sputum induction and handling and, therefore, to a different relative dilution of sputum samples with saliva and saline. The possibility also exists that the two study groups were not clinically matched.

We did not analyse sputum gel phase, so we cannot exclude differences with respect to composition of sputum gel phase (SGP) and sputum sol phase (SSP). However, other authors have shown that the inclusion of SGP protein levels does not affect the variation of sputum protein analysis in patients with stable asthma and chronic obstructive pulmonary disease (COPD) [23].

The possibility that the inhalation of histamine may influence eosinophil and ECP levels is not supported by the present data, in line with previous results [24].

Some studies using sputum of asthmatics [12, 25] have shown a relationship between eosinophils on the one hand and baseline airway obstruction and BHR on the other. On the contrary, in other studies [16] eosinophil differential counts did not relate to functional data. Although the reasons for these discrepancies are likely to be complex, differences in clinical and functional characteristics of patients and a time lag between changes in inflammatory profile and measurement of functional parameters (FEV1, PC20) are not unlikely factors $[26,27]$. In a recent study, sputum ECP, but not sputum eosinophils, related to FEV1 [16], so that sputum ECP was considered a more sensitive index than eosinophils in reflecting active airway inflammation, and thereby airway obstruction. The latter study [16], however, was based on a small sample of patients with a lack of clinical information: clinical scores, BHR and duration of disease. In addition, in the study by VIRCHOw et al. [16], the observation that some patients who were not treated with steroid exhibited a $<10 \%$ FEV 1 reversibility after $\beta_{2}$-agonists does not seem to be consistent with the diagnosis of pure bronchial asthma. The present study, carried out in a well-defined asthmatic group, seems to indicate: firstly, that the activity of eosinophils, estimated by ECP levels in sputum, was highly related 
to the number of eosinophils, even though in a small percentage of patients with no eosinophils the ECP level appeared to be higher than that calculated for the normal control group. Secondly, the relationship of neither of the two sputum outcomes with baseline airway obstruction was clinically meaningful. Thirdly, the data extend the results of previous studies, in that neither eosinophils nor ECP accurately reflect the clinical severity of the disease in patients with chronic stable asthma.

BHR is a cardinal feature of asthma and has been recognized to relate to severity of disease, frequency of exacerbation and the need for treatment [28]. In the present study, sputum eosinophils did not relate to, and sputum ECP was only weakly related to, the degree of BHR as assessed in terms of PC20. These results suggest that sputum expression of eosinophil airway inflammation is not identical to BHR and that other factors, such as airway remodelling, are involved in determining the level of BHR [29-31]. Thus, the sputum and the degree of BHR may provide complementary information in well-controlled asthmatic patients.

The role of blood eosinophil counts and serum ECP in monitoring disease activity in chronic asthma is not well defined [6-10]. In the present study, serum ECP was higher in asthmatic patients than in normal subjects, but neither of the two blood outcomes related to the clinical score or baseline pulmonary function.

In conclusion, although sputum eosinophils and eosinophilic cationic protein did not accurately discern disease severity subgroups, they provided a direct method for investigating airway inflammation. Repeated measurements may be useful for monitoring the inflammatory process and the response to therapy in the individual patient.

\section{References}

1. Beasley R, Roche WR, Roberts JA, Holgate ST. Cellular events in the bronchi in mild asthma and after provocation. Am Rev Respir Dis 1989; 139: 806-817.

2. Jeffery PK, Godfrey RW, Alderoth E, Nelson F, Rogers A, Jahansson SA. Effects of treatment on airway inflammation and thickening of basement membrane reticular collagen in asthma. Am Rev Respir Dis 1992; 145: 890-899.

3. Laitinen LA, Laitinen A, Haahtela T. Airway mucosal inflammation even in patients with newly diagnosed asthma. Am Rev Respir Dis 1993; 147: 697-704.

4. Venge P, Dahl R, Fredens K, Peterson C. Epithelial injury of human eosinophils. Am Rev Respir Dis 1988; 138: S54-S57.

5. Gleich GJ, Flavahan NA, Fujisawa T, Vanhoutte PM. The eosinophil as a mediator of damage to respiratory epithelium: a model for bronchial hypersensitivity (Aspen Allergy Conference). J Allergy Clin Immunol 1988; 81: 776-781.

6. Horn BR, Robin ED, Theodore J, Van Kessel A. Total eosinophil counts in the management of bronchial asthma. N Engl J Med 1975; 29: 1152-1155.

7. Venge P. Serum measurements of eosinophil cationic protein (ECP) in bronchial asthma. Clin Exp Allergy 1993; 23 (Suppl. 2): 3-7.

8. Bousquet J, Chanez P, Lacoste JY, et al. Eosinophil inflammation in asthma. N Engl J Med 1990; 323: 1033-1039.

9. Wever AMJ, Wever-Hess J, Hensgenst HESJ, Hermans J. Serum eosinophil cationic protein (ECP) in chronic asthma: relationship to spirometry, flow-volume curves, PC20, and exacerbations. Respir Med 1994; 88: 613-621.

10. Ferguson AC, Vaughan R, Brown H, Curtis C. Evaluation of serum eosinophilic cationic protein as a marker of disease activity in chronic asthma. J Allergy Clin Immunol 1995; 95: 23-28.

11. Gibson PJ, Girgis-Gabardo A, Morris MM, et al. Cellular characteristics of sputum from patients with asthma and chronic bronchitis. Thorax 1989; 44: 693-699.

12. Pin I, Gibson PG, Kolendowicz R, et al. Use of sputum cell counts to investigate airway inflammation in asthma. Thorax 1992; 47: 25-29.

13. Fahy JV, Liu J, Wong H, Boushey HA. Cellular and biochemical analysis of induced sputum from asthmatics and from healthy subjects. Am Rev Respir Dis 1993; 147: 1126-1131.

14. Popov T, Gottschalk R, Kolendowicz R, Dolovich J, Powers P, Hargreave FE. The evaluation of a cell dispersion method of sputum examination. Clin Exp Allergy 1995; 24: 778-783.

15. Alderoth E, Rosenhall, Johansonn S, Linden M, Venge P. Inflammatory cells and eosinophilic activity in asthmatics investigated by bronchoalveolar lavage. Am Rev Respir Dis 1990; 142: 91-99.

16. Virchow JC Jr, Holscher V, Virchow C Sr. Sputum ECP levels correlate with parameters of airflow obstruction. Am Rev Respir Dis 1992; 146: 604-606.

17. NHLBI. International consensus report on diagnosis and management of asthma. Publication No. 92-3091. Bethesda, Maryland 20892, USA: National Heart, Lung and Blood Institute, National Institutes of Health. Eur Respir $J$ 1992; 5: 601-641.

18. Aas K. Heterogeneity of bronchial asthma. Allergy 1981; 36: 3-14.

19. Scano G, Garcia Herreros P, Stendardi D, Degre S, De Coster A, Sergysels R. Cardiopulmonary adaptation to exercise in coal miners. Arch Environ Health 1980; 35: 360-366.

20. European Coal and Steel Community. Standardization of lung function tests. Eur Respir J 1993; 6 (Suppl. 16): 1-100.

21. Ronchi MC, Piragino C, Rosi E, Amendola M, Duranti R, Scano G. Role of sputum differential count in detecting airway inflammation in patients with chronic bronchial asthma. Thorax 1996; 51: 1000-1004.

22. Bland JM, Altman DG. Statistical methods for assessing agreement between two methods of clinical measurement. Lancet 1986; i: 307-310.

23. Schoonbrood DF, Lutter R, Habets FJ, Roos CM, Jansen HM, Out TA. Analysis of plasma-protein leakage and local secretion in sputum from patients with asthma and chronic obstructive pulmonary disease. Am J Respir Crit Care Med 1994; 150: 1519-1527.

24. Söderberg M, Lundgren R, Bjermer L, Stjernberg N, Rosenhall $\mathrm{L}$. Inflammatory response in bronchoalveolar lavage fluid after inhaling histamine. Allergy 1989; 44: 98-102.

25. Pin I, Radford S, Kolendowicz R, et al. Airway inflammation in symptomatic and asymptomatic children with methacholine hyperresponsiveness. Eur Respir J 1993; 6: 1249-1256.

26. Baigelman W, Chodosh S, Pizzuto D, Cupples LA. Sputum and blood eosinophils during corticosteroid treatment of acute exacerbations of asthma. Am J Med 1983; 75: 929-935.

27. Pin I, Freitag AP, O'Byrne PM, et al. Changes in the cellular profile of induced sputum after allergen-induced asthmatic responses. Am Rev Respir Dis 1992; 145: 1265-1269.

28. Woolcock AJ, Peat JK, Salome CM. Prevalence of bronchial hyperresponsiveness and asthma in a rural adult population. Thorax 1987; 42: 361-368.

29. Moreno RH, Hogg J, Paré PD. Mechanics of airway narrowing. Am Rev Respir Dis 1986; 133: 1171-1180.

30. Paré PD, Bai TR. The consequences of chronic allergic inflammation. Thorax 1995; 50: 328-332.

31. Chetta A, Foresi A, Del Donno M, et al. Bronchial responsiveness to distilled water and methacholine and its relationship to inflammation and remodelling of the airways in asthma. Am J Respir Crit Care Med 1996; 153: 910-917. 